\title{
Improvement of Prefrontal Brain Function in Endogenous Psychoses Under Atypical Antipsychotic Treatment
}

\author{
Ann-Christine Ehlis*,', Martin J Herrmann', Paul Pauli', Gerald Stoeber', Bruno Pfuhlmann' and \\ Andreas J Fallgatter' \\ 'Department of Psychiatry and Psychotherapy, University of Wuerzburg, Wuerzburg, Germany; ${ }^{2}$ Department of Psychology I, University of \\ Wuerzburg, Wuerzburg, Germany
}

\begin{abstract}
Typical and atypical antipsychotics are thought to exert their effects on different neurotransmitter pathways with specific action of atypical compounds on the prefrontal cortex, but studies directly investigating the effect of those drugs on neurophysiological measures of prefrontal brain function are sparse. We therefore investigated the influence of different antipsychotics on an electrophysiological marker of prefrontal brain function (NoGo anteriorization, NGA) and neuropsychological test scores. For this purpose, 38 patients with endogenous psychoses were investigated at the beginning of a stationary psychiatric treatment and at a 6-week-follow-up. Patients were treated with typical or atypical antipsychotics, or a combination of both. They underwent psychopathological diagnostic and neuropsychological testing, as well as electrophysiological investigations during a Continuous Performance Test. The results indicate that typical and atypical antipsychotics differentially affected the development of the NGA over the course of the treatment, typical antipsychotics tending to result in decreased values at follow-up, and atypical antipsychotics stabilizing, or increasing this parameter. Performance in tests of frontal lobe function generally declined under typical antipsychotics and improved with atypical compounds, changes in Stroop interference correlated with changes in the NGA. We conclude that typical and atypical antipsychotics differ regarding their effect on prefrontal brain function in schizophrenia, atypical neuroleptics often showing a more favorable impact than conventional antipsychotics on respective parameters.

Neuropsychopharmacology (2007) 32, 1669-1677; doi:I 0.1038/sj.npp. I 301293; published online 3 Janaury 2007
\end{abstract}

Keywords: schizophrenia; prefrontal cortex; antipsychotics; event-related potentials (ERP); response inhibition; anterior cingulate cortex (ACC)

\section{INTRODUCTION}

Since introduction of the hypofrontality concept (Ingvar and Franzen, 1974), a dysfunction of prefrontal brain areas in schizophrenic patients has frequently been found with many different methodological approaches (eg, Andreasen et al, 1992; Carter et al, 1998; Fallgatter and Mueller, 2001; Goldberg et al, 1993; Riley et al, 2000). Besides the dorsolateral prefrontal cortex (DLPFC), which has frequently been implicated in schizophrenic illnesses (Glahn et al, 2005; MacDonald and Carter, 2003; RodriguezSanchez et al, 2005), particularly the anterior cingulate

This work is part of the dissertation of A-C Ehlis, supervised by P Pauli, Department of Psychology I (Biological Psychology), University of Wuerzburg.

*Correspondence: Dr A-C Ehlis, Laboratory for Psychophysiology and Functional Imaging, Department of Psychiatry and Psychotherapy, University of Wuerzburg, Fuechsleinstraße 15, 97080 Wuerzburg, Germany, Tel: + 4993120177410 , Fax: + 4993120177550 ,

E-mail: Ehlis_A@klinik.uni-wuerzburg.de

Received 21 July 2006; revised 16 October 2006; accepted 2 November 2006 cortex (ACC) is assumed to be affected by this hypofrontality, which has been shown with different neuroimaging techniques at rest (Tamminga et al, 1992) as well as during activation with neuropsychological tasks (Andreasen et al, 1992; Carter et al, 1997; Dolan et al, 1995; Haznedar et al, 1997; Siegel et al, 1993; Tamminga et al, 1992).

The availability of so-called 'atypical' antipsychotics broadened the therapeutic possibilities in the treatment of psychoses from the schizophrenic spectrum. The bestfounded theoretical concept explaining differences in the way of action between typical and atypical antipsychotics focuses on the neurotransmitter systems addressed. Typical antipsychotics are thought to reduce positive symptoms like delusions and hallucinations mainly by blocking D2 receptors in the mesolimbic dopaminergic system. Atypical antipsychotics are supposed to additionally improve negative and cognitive symptoms by a supplementary action on neurotransmitter systems within the prefrontal cortex (Díaz-Mataix et al, 2005; Horacek et al, 2006; Ichikawa and Meltzer, 1999). Such a differential action on the prefrontal cortex is supported by neuropsychological studies indicating an improvement of cognitive perfor- 
mance during therapy with atypical compounds as compared to a poor response or even an exacerbation under typical antipsychotics (Borison, 1996; Gur et al, 2003; Lewander, 1994; Purdon et al, 2000), although even within the group of atypical antipsychotics substances seem to differ regarding their exact effects (eg, Woodward et al, 2005). Studies directly investigating the effect of medication not only on cognition but also on underlying prefrontal brain function are sparse. However, a recent ${ }^{1} \mathrm{H}$-Magnetic resonance spectroscopic imaging study described higher levels of $\mathrm{N}$-acetylaspartate in the ACC of schizophrenic patients treated with atypical as compared to typical neuroleptics. This finding indicated a more pronounced neuronal viability in the atypical group and was accompanied by a better neuropsychological performance (Braus et al, 2002).

During the last years we developed an electrophysiological marker of prefrontal cortex function termed NoGo anteriorization (NGA) (Fallgatter et al, 1997). Based on event-related potentials (ERP) derived from a multichannel EEG during performance of a Go-NoGo task, the NGA quantitatively describes the amount of anteriorization of the positive brain electrical field associated with the inhibition (NoGo condition) relative to the execution (Go condition) of a prepared motor response. In healthy subjects, the NGA has been shown to have a very high interindividual stability (Fallgatter et al, 1997, 2000; Fallgatter and Strik, 1999), an excellent short- (Fallgatter et al, 2001), and long-term testretest reliability (Fallgatter et al, 2002a), and it appears to be independent of the participant's age and gender (Fallgatter et al, 1999). Moreover, three-dimensional source localization studies with the LORETA method (Low Resolution Electromagnetic Tomography; Pascual-Marqui et al, 1994) repeatedly found a significantly higher activation within prefrontal brain areas (particularly the ACC) during the response inhibition (NoGo) as compared to the response execution (Go) condition as the basis of the NGA (Strik et al, 1998; Fallgatter et al, 2002b). This finding is in line with PMRI and PET studies that also reported increased activation of the ACC during inhibitory processes (de Zubicaray et al, 2000; Ford et al, 2004; Matthews et al, 2004; Rubia et al, 2001). Based on these findings, the NGA has been suggested to be an electrophysiological correlate of prefrontal response control probably associated with activation of the ACC.

Compared to age- and gender-matched healthy controls, schizophrenic patients were found to have a significantly reduced mean NGA (Fallgatter and Mueller, 2001) and a significantly diminished activation of the ACC during processes of response inhibition as indicated by a LORETA source localization (Fallgatter et al, 2003). This electrophysiological finding is once again in line with findings obtained by other neuroimaging methods that similarly reported reduced activation in the ACC region in schizophrenic patients during processes of response inhibition and executive control (Carter et al, 2001; Laurens et al, 2003; Rubia et al, 2001; Volz et al, 1999).

The present study was designed to evaluate the effect of atypical $v s$ typical antipsychotic treatment of 6 weeks duration in acutely admitted patients with endogenous psychoses. Prefrontal brain function was assessed with the NGA, and cognitive performance was measured with the
Stroop task (cognitive interference) and the Verbal Fluency Test (VFT; word fluency). Based on the findings described above we hypothesized that treatment with atypical antipsychotics should lead to a more pronounced improvement in both prefrontal brain function (ie, higher NGA values) and cognitive performance (ie, better performance measures in neuropsychological tests of frontal lobe function) as compared to treatment with typical antipsychotics.

\section{PATIENTS AND METHODS}

\section{Participants}

Acutely admitted patients who were suspected to suffer from a schizophrenic disorder were included. Exclusion criteria were age below 18 and above 60 years, actual pretreatment with atypical antipsychotics, significant comorbidities with other currently present axis I disorders, a history of or an actually manifest disease of the CNS, or severe somatic diseases. Electrophysiological and neuropsychological investigations took place within 3 days after admittance to the hospital (baseline) and at a 6-weekfollow-up. Forty-three patients completed both assessments with sufficient performance. Four patients had to be disclosed because of too many artifacts in at least one of the electrophysiological investigations, one other patient refused any neuroleptic treatment. From the remaining 38 patients (22 females; 33 right handed, five left handed; mean age $35.7 \pm 10.8$ years) a minimum of 20 artifact-free EEG-epochs after the Go and the NoGo condition of the Continuous Performance Test (CPT) were available.

According to the SKID-I-Interview (Wittchen et al, 1997) these patients were diagnosed as suffering from disorganized $(295.10 ; n=4)$, catatonic $(295.20 ; n=1)$, paranoid $(295.30 ; n=8)$, and undifferentiated $(295.90 ; n=4)$ types of schizophrenia. Because of the time criteria in DSM-IV, part of the patients was diagnosed as suffering from schizophreniform disorders $(295.40 ; n=14)$. Six patients were diagnosed with a schizoaffective disorder (295.70) and one patient with a psychotic disorder, not otherwise specified (298.9). With regard to psychiatric comorbidities, two patients were diagnosed with a Cannabis abuse (305.20), one with Bulimia nervosa (307.51), one patient had suffered from a polysubstance dependence in the past (304.80), one from sedative abuse (305.40), and another one from anorexia nervosa (307.1). The mean duration of the disease was $123.9 \pm 107.8$ months, the number of admissions to psychiatric hospitals was $4.8 \pm 6.1$, and the mean duration of all hospitalizations combined was $9.8 \pm 12.0$ months. Only five patients had a positive family history for schizophrenia with an affected first-degree relative. CT and/or MRI scans as rated by an experienced neuroradiologist revealed indications for a mild-to-moderate brain atrophy in five patients. Electroencephalographic examinations disclosed a modest slowing of the basic rhythm in eight cases. Regarding their social and educational status, patients had a mean of $10.34 \pm 1.99$ years of school education; the sample consisted of five university students, four university graduates, 25 patients with a completed professional training, and four patients without any learned profession.

The choice of medication in this clinical setting was fully up to the treating physicians on the wards, who were blind 
with respect to all neurophysiological and neuropsychological results. The investigators in the neurophysiological laboratory, on the other hand, were not informed about the patients' medication status. 10 patients $(37.2 \pm 14.6$ years, five female, 10 right handed) received neuroleptic treatment with typical antipsychotics (flupentixol, perazine, melperone, chlorprothixene, perphenazine; mean chlorpromazineequivalents $(\mathrm{CPZ})$ of $488.6 \pm 222.6 \mathrm{mg} / \mathrm{d}), 19(34.4 \pm 9.1$ years, 11 female and 17 right handed) were treated with atypical neuroleptics (clozapin, olanzapine, risperidone, solian, seroquel, ziprasidon; CPZ of $527.0 \pm 324.1 \mathrm{mg} /$ day) and nine $(36.9 \pm 10.5$ years, six female, six right handed) were under a combination of atypical and typical antipsychotics (four risperidone + perazine, three risperidone + perazine + flupentixol, one risperidone + pipamperone + amisulpride, one melperone + perazine + risperidone; $\mathrm{CPZ}$ of $681.7 \pm 419.4 \mathrm{mg} /$ day). The type of antipsychotic medication was held constant over the course of the treatment, although adjustments in dosages occurred in most patients, particularly around the beginning of the treatment period. $\mathrm{CPZ}$ equivalents were calculated according to the specifications of Laux et al (2000) on clinical empirical equivalent doses of antipsychotic drugs; values for ziprasidon were calculated on the basis of a publication on newer atypical antipsychotics by Woods (2003).

Additionally, at some point during their stationary treatment 28 of the patients were on low to medium doses of benzodiazepines, 17 received an antidepressant therapy, six patients were treated with carbamazepine, nine with valproat, six with lithium, and six with biperiden. The three patient groups were very similar with respect to this adjunctive medication; there was only one significant difference between the groups as indicated by a $\chi^{2}$ statistic $\left(\chi^{2}=6.14, p<0.05\right)$ with almost half of the typically medicated patients but only one patient in each of the other two groups receiving lithium as co-medication. Regarding general demographic variables, the three groups of patients did not differ significantly regarding their mean age $(t<0.7, p>0.5)$ or gender distribution $\left(\chi^{2}=0.54, p=0.76\right)$; a trend for a difference in the distribution of the handedness occurred $\left(\chi^{2}=4.84\right.$, $p=0.09)$. Written informed consent was obtained from all patients after the procedures had been fully explained. The study was approved by the Ethics Committee of the University of Wuerzburg, and the procedures involved were in accordance with the Declaration of Helsinki Principles.

\section{Psychopathological Assessment}

An extensive psychopathological and psychometric investigation was performed with each patient consisting of the SKID-I-Interview, the Brief Psychiatric Rating Scale (BPRS; Overall and Gorham, 1962), the Positive and Negative Syndrome Scale (PANSS; Kay et al, 1987), and the Hamilton Depression Rating Scale/24 Items (HDRS; Hamilton, 1960).

\section{Neuropsychological Investigation}

Each neuropsychological assessment consisted of the VFT and the Stroop Color Word Task (Stroop, 1935). For the
VFT, patients were instructed to name as many nouns as possible beginning with a certain letter (A, F, and $S$; $1 \mathrm{~min}$ each $=$ 'letters version') or belonging to a certain category of words (animals, fruits, and flowers; 1 min each = 'categories version'). Performance of the VFT has been suggested to involve Broca's area and prefrontal brain structures such as the DLPFC (Cuenod et al, 1995; Dickins et al, 2001; Gaillard et al, 2000).

The Stroop Color Word Task consisted of three parts: For the first part ('word reading'), patients had to read color words (German words for 'blue', 'red', 'green', and 'yellow') that were printed in black ink on a white sheet. For the second part ('color naming'), they had to name the colors of blue, red, green, and yellow lines as quickly as possible. The third part of the test ('interference condition') consisted of color words printed in an ink color that did not correspond to the word meaning of the color word (eg, the word 'blue' printed in red ink). Patients were instructed to simply name the ink color of the words. The time needed to complete this last condition has been suggested to reflect activity of prefrontal brain areas, particularly the ACC (Barch et al, 2001; Ruff et al, 2001; Swick and Jovanovic, 2002), stronger cognitive interference (which is usually reflected by longer reaction times) resulting in more pronounced prefrontal activation. The Stroop effect is a universal phenomenon that mirrors cognitive interference induced by conflicting stimuli; individuals differ regarding their susceptibility to being distracted by interfering conditions.

\section{Electrophysiological Investigation}

Patients performed the CPT (Rosvold et al, 1956) during registration of the ongoing EEG in a dimly lit, sound attenuated and electrically shielded room. On a computer screen $60 \mathrm{~cm}$ in front of them, letters were presented sequentially in a pseudo-randomized order. The letters on the screen were $12 \mathrm{~mm}$ high and $11 \mathrm{~mm}$ wide, resulting in a visual angle of $1.15^{\circ}$ horizontally and $1.05^{\circ}$ vertically. Subjects were instructed to press a response button only when the letter $\mathrm{O}$ was directly followed by the letter $\mathrm{X}$. Speed and accuracy were emphasized equally during explanation of the test. A short training session was performed to ensure correct understanding of the instructions. The applied $\mathrm{O}-\mathrm{X}$ version of the $\mathrm{CPT}$ consisted of a total of 400 letters (114 letters $\mathrm{O}=$ primer condition, $57 \mathrm{X}$ following an $\mathrm{O}=\mathrm{Go}$ condition, 57 other letters following an $\mathrm{O}=$ NoGo condition, and 172 letters not following an $\mathrm{O}=$ distractors) with a stimulus-onset asynchrony of $1850 \mathrm{~ms}$ and a presentation time of $200 \mathrm{~ms}$ each. Simultaneously, the EEG was recorded from 21 scalp electrodes placed according to the International 10/20 System. Three additional electrodes were attached at the outer canthi of both eyes and below the right eye for registration of eye movements. The technical equipment consisted of a 32-channel DC amplifier (Brain-Star system, Erlangen, Germany) and a data acquisition software (Neuroscan, Sterling, VA), which was calibrated with an external $100 \mu \mathrm{V} /$ $10 \mathrm{~Hz}$ signal. The hardware filter was set to a bandpass from $0.1-70 \mathrm{~Hz}, \mathrm{~A} / \mathrm{D}$ rate was $256 \mathrm{~Hz}$. Recording references were linked mastoids. All electrode impedances were below $5 \mathrm{k} \Omega$. 


\section{Data Analysis}

Data analysis was performed with the program 'Vision Analyzer' (Brain Products, Munich, Germany). After a filtering from $0.1-70 \mathrm{~Hz}$ and re-referencing of the data to an average reference, a correction for ocular artifacts (Gratton and Coles, 1989) was executed. After a computerized artifact rejection (only amplitudes $<50 \mu \mathrm{V}$ were allowed in all EEG channels within $100 \mathrm{~ms}$ before and $700 \mathrm{~ms}$ after stimulus presentation), the artifact-free epochs after correct responses were segmented and averaged to one Go and one NoGo ERP per subject. For the Nogo ERP, the time point of the most positive peak at electrode position $\mathrm{Cz}$ within a P300 time window $(275-530 \mathrm{~ms})$ was used to calculate the two-dimensional topography by means of the centroid method (Lehmann, 1987), whereas the respective peak at electrode position $\mathrm{Pz}$ was used for the Go-condition. The location of each individual centroid on an anterior-posterior axis was determined by numbers from 1 (level of electrode position $\mathrm{Fpz}$ ) to 5 (level of $\mathrm{Oz}$ ) as illustrated in Figure 1 (locations somewhere in between two electrode positions were expressed by respective decimal numbers). The smaller the numbers decoding the centroid location, the more anterior is their location. For a more detailed description of the centroid method, please confer the work of Lehmann (1987) and our previous publications (Fallgatter $e t a l, 2001)$. The individual NGA was calculated as the difference between Go and NoGo centroid in the anteriorposterior axis. The grand average curves of the group of patients as a whole are shown in Figure 1, along with a schematic illustration of this quantification of the NGA as the geometrical distance between Go and NoGo centroid.

\section{Statistical Analysis}

All statistical analyses were performed with the software SPSS for Windows (version 13.0). For the CPT reaction times, the NGA, and the Verbal Fluency scores $2 \times 3$ analyses of variance (ANOVAs) for repeated measurements were conducted comprising the inner-subject factor 'time'

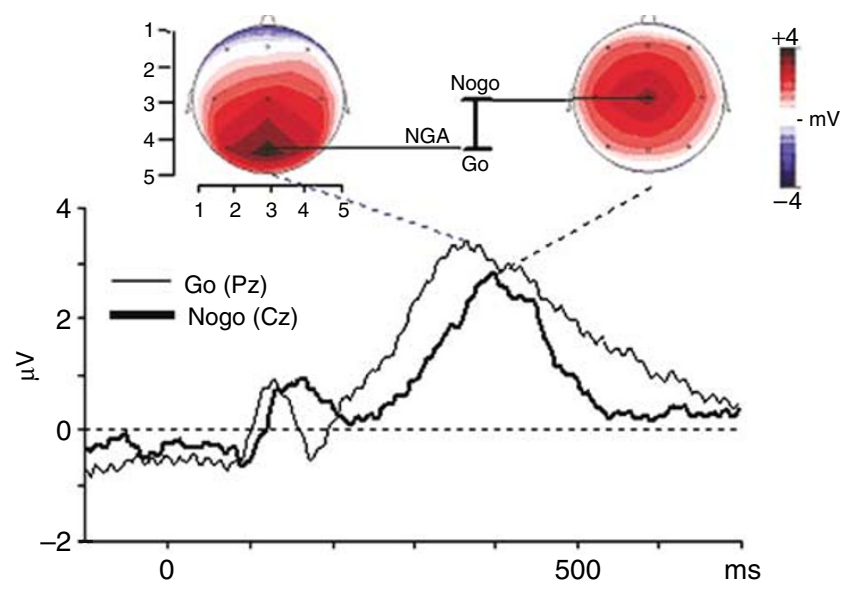

Figure I Grand average curves of Go (Pz; thin line) and Nogo (Cz; bold line) trials at the baseline measurement for the group of patients as a whole $(n=38)$. Maps illustrate the distribution of the positive brain electrical field at the respective peak of the P300. Schematic illustration of the quantification of the NGA as the geometrical distance between Go and Nogo centroid in the anterior-posterior direction. (baseline $v s$ 6-week-follow-up) and the between-subject factor 'medication' (typical $v s$ atypical $v s$ combined antipsychotics). Regarding the Stroop task, we created two difference scores (Stroop interference time minus Stroop color naming and Stroop word reading time, respectively), to control for nonspecific effects of typical antipsychotic medication on reaction times and overall task engagement, and to specifically analyze the interference effect of the Stroop task. The two difference measures were then subjected to two-factorial ANOVAs ('time $\times$ medication') as described above. The Greenhouse-Geisser procedure was used to correct the degrees of freedom whenever necessary. Post hoc analyses were conducted using two-tailed $t$-tests for matched or independent samples; equality of variances was tested by means of Levene's test and corrections for unequality were performed when necessary. As the error rates in the CPT and the Stroop interference condition were not normally distributed, the Kruskal-Wallis test and the Wilcoxon's test were used for between-group and withingroup comparisons. Correlations between the change in the NGA and changes in neuropsychological and psychometric variables from baseline to follow-up were calculated with parametric (Pearson) or non-parametric (Spearman) methods depending on whether the variables were normally distributed.

\section{RESULTS}

\section{Psychopathological Results}

The results of the psychopathological examinations (BPRS, PANSS, and HDRS) are summarized in Table 1; 'pre' and 'post' indicate scores at the beginning of the study and at the 6-week-follow-up, results are shown separately for the three groups of patients (typical, atypical, and combined antipsychotics). ANOVAs for repeated measurements were conducted to examine the influence of the factors 'time' and 'medication' on the clinical ratings. For all the variables (BPRS, PANSS positive/negative/global and total score, and HDRS) the main result was the same: a significant main effect of the factor 'time' (baseline $v s$ follow-up) was observed (PANSSneg: $F_{1,35}=8.73, p<0.01$; rest: $\mathrm{F}_{1,35}>40.0, p<0.001$ ), with no main effect 'medication' $\left(\mathrm{F}_{2,35}<1.8, p>0.18\right)$ and no significant interaction between the two factors $\left(\mathrm{F}_{2,35}<0.7, p>0.5\right)$.

\section{Performance Measures}

The reaction times and error rates of the three groups of patients are displayed in Table 2, separately for the first CPT measurement and the follow-up examination. Commission errors occurred whenever a patient responded to a nontarget stimulus; omission errors consisted of Go conditions the patient did not respond to. For the reaction times to Go stimuli, an ANOVA with the factors 'time' and 'medication' revealed no significant main effects ('time': $\mathrm{F}_{1,35}=0.59$, NS; 'medication': $\mathrm{F}_{2,35}=0.02, \mathrm{NS}$ ) and no significant interaction between the two factors $\left(\mathrm{F}_{2,35}=1.48, \mathrm{NS}\right)$. The commission and omission error rates were not normally distributed, but a Kruskal-Wallis test revealed that the three groups of patients did not differ significantly regarding their error rates in the baseline or follow-up measurement $(p>0.15)$. 
Table I Psychometric Results

\begin{tabular}{|c|c|c|c|}
\hline & Typical $(n=10)$ & Atypical $(n=19)$ & Combined $(n=9)$ \\
\hline \multicolumn{4}{|l|}{ HDRS } \\
\hline Pre & $8.4 \pm 3.9$ & $|I| \pm 4.8$. & $8.1 \pm 4.1$ \\
\hline Post & $5.5 \pm 4.0$ & $6.7 \pm 4.4$ & $4.2 \pm 2.3$ \\
\hline \multicolumn{4}{|l|}{ BPRS } \\
\hline Pre & $35.5 \pm 7.4$ & $37.9 \pm 11.6$ & $32.9 \pm 5.1$ \\
\hline Post & $28.1 \pm 7.0$ & $30.4 \pm 7.4$ & $26.0 \pm 3.3$ \\
\hline \multicolumn{4}{|l|}{ PANSS } \\
\hline \multicolumn{4}{|l|}{ Tot } \\
\hline Pre & $57.7 \pm 10.9$ & $60.6 \pm 19.1$ & $53.4 \pm 8.2$ \\
\hline Post & $46.3 \pm 9.8$ & $48.5 \pm 12.5$ & $43.4 \pm 5.1$ \\
\hline \multicolumn{4}{|l|}{ Pos } \\
\hline Pre & $12.8 \pm 5.5$ & $14.0 \pm 4.7$ & $11.9 \pm 3.4$ \\
\hline Post & $9.3 \pm 3.2$ & $9.9 \pm 3.4$ & $8.3 \pm 1.8$ \\
\hline \multicolumn{4}{|l|}{$\mathrm{Neg}$} \\
\hline Pre & $13.7 \pm 2.8$ & $14.4 \pm 7.2$ & $13.3 \pm 4.2$ \\
\hline Post & $11.5 \pm 2.7$ & $12.2 \pm 4.0$ & $11.9 \pm 2.6$ \\
\hline \multicolumn{4}{|l|}{ Glob } \\
\hline Pre & $31.2 \pm 6.5$ & $32.2 \pm 9.5$ & $28.2 \pm 5.3$ \\
\hline Post & $25.5 \pm 6.7$ & $26.4 \pm 7.4$ & $23.2 \pm 3.4$ \\
\hline
\end{tabular}

Regarding the change in error rates from baseline to followup within the three groups of patients, the Wilcoxon's test indicated a significant improvement only for the number of commission errors in the group of atypically medicated patients $(Z=-2.04, p<0.05)$.

\section{NGA}

Regarding the NGA, a two-factorial ANOVA revealed a significant interaction between the factors 'time' and 'medication' $\left(\mathrm{F}_{2,35}=6.95, p<0.01\right)$, which is in accordance with our hypotheses. Patients treated with typical antipsychotics showed a trend to a decrease of the NGA over time $\left(\mathrm{NGA}_{\text {baseline }}=0.75, \quad \mathrm{NGA}_{\text {follow-up }}=0.39, t_{9}=2.21\right.$, $p=0.055)$, whereas patients treated with atypical antipsychotics were characterized by a stabilization or even an increase in the NGA (atypical antipsychotics alone: $\mathrm{NGA}_{\text {baseline }}=0.71, \quad \mathrm{NGA}_{\text {follow-up }}=0.87, t_{18}=-1.55, \quad \mathrm{NS}$; combined antipsychotics: $\mathrm{NGA}_{\text {baseline }}=0.65, \mathrm{NGA}_{\text {follow- }}$ up $=1.04, t_{8}=-2.86, p<0.05$ ) (Figure 2). Further post-hoc tests revealed that the group of patients treated with typical antipsychotics initially (baseline) did not differ from patients under atypical antipsychotics or from the group with a combined treatment $\left(t_{17}=0.21\right.$, NS and $t_{27}=0.46$, NS), whereas the typical group showed a significantly diminished NGA at follow-up as compared to the atypical $\left(t_{27}=2.72, p<0.05\right)$ as well as the combined group $\left(t_{17}=2.97, p<0.01\right)$. The atypical and the combined group
Table 2 Performance in the CPT

\begin{tabular}{lccc}
\hline & Typical $(\mathbf{n}=\mathbf{l 0})$ & Atypical $(\mathbf{n}=\mathbf{l 9})$ & Combined $(\mathbf{n}=\mathbf{9})$ \\
\hline$R T(\mathrm{~ms})$ & & & \\
Pre & $581 \pm 160$ & $602 \pm 204$ & $548 \pm 102$ \\
Post & $592 \pm 169$ & $578 \pm 112$ & $609 \pm 116$ \\
& & & \\
Com. errors & & & $2.3 \pm 3.2$ \\
Pre & $1.2 \pm 1.7$ & $6.9 \pm 21.0$ & $2.0 \pm 3.3$ \\
Post & $0.7 \pm 0.8$ & $0.7 \pm 1.1$ & \\
& & & $11.2 \pm 11.8$ \\
Om. errors & & $6.2 \pm 7.1$ & $12.0 \pm 9.5$ \\
Pre & $6.9 \pm 6.0$ & $5.5 \pm 6.3$ & \\
Post & $7.8 \pm 6.8$ & & \\
\hline
\end{tabular}

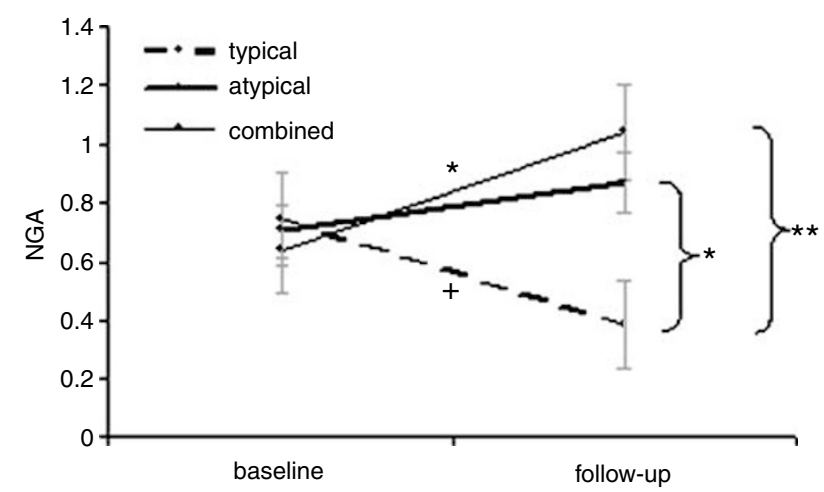

Figure 2 Mean NGA at baseline and after 6 weeks of treatment with typical $(n=10)$, atypical $(n=19)$, or combined $(n=9)$ antipsychotics (follow-up). Significant differences and trends for differences between groups (next to the brackets) and over time (above or below respective lines) were marked $\left({ }^{*} p<0.05,{ }^{*} * p<0.01,{ }^{+} p<0.1\right)$. Standard errors are indicated by grey vertical lines.

did not differ from each other, neither at baseline $\left(t_{26}=0.38\right)$ nor at follow-up $\left(t_{26}=0.94, \mathrm{NS}\right)$.

\section{Neuropsychological Results}

$V F T$. For the number of words named in the letters version of the VFT, the two-factorial ANOVA revealed a significant main effect 'time' $\left(\mathrm{F}_{1,35}=4.64, p<0.05\right)$ as well as a significant interaction between the factors 'time' and 'medication' $\left(\mathrm{F}_{2,35}=4.43, p<0.05\right)$. In the typically medicated group of patients the number of words decreased from 27.7 at baseline to 25.2 at follow-up ( $t_{9}=1.31$, NS), whereas there was an increase in this measure for the atypical group $\left(t_{18}=3.21, p<0.01\right)$ and also for the combined group $\left(t_{8}=1.96, p<0.1\right.$; cf. Table 3$)$. For the categories version no significant main effects occurred, but again a significant interaction between the factors 'time' and 'medication' was found $\left(\mathrm{F}_{2,35}=4.70, p<0.05\right)$. With a significant decrease in the number of words achieved by the typical group $\left(t_{9}=4.05, p<0.01\right)$, tendencies for increases of this measure were found for the atypically medicated group $\left(t_{8}=2.02, p<0.1\right)$ as well as the combined group $\left(t_{8}=1.56, \mathrm{NS}\right.$; cf. Table 3$)$. 
Table 3 Neuropsychological Data

\begin{tabular}{|c|c|c|c|}
\hline & Typical $(n=10)$ & Atypical $(n=19)$ & Combined $(n=9)$ \\
\hline \multicolumn{4}{|l|}{ VFT } \\
\hline \multicolumn{4}{|l|}{ Letters } \\
\hline Pre & $27.7 \pm 8.2$ & $26.3 \pm 9.8$ & $23.0 \pm 13.0$ \\
\hline Post & $25.2 \pm 7.0$ & $31.8 \pm 7.9 * *$ & $27.9 \pm 14.6^{+}$ \\
\hline \multicolumn{4}{|l|}{ Categ. } \\
\hline Pre & $40.8 \pm 6 . a v 9$ & $34.1 \pm 9.4$ & $34.7 \pm 12.6$ \\
\hline Post & $35.5 \pm 5.9 * * *$ & $38.9 \pm 9.2^{+}$ & $39.6 \pm 12.5$ \\
\hline \multicolumn{4}{|l|}{ Stroop } \\
\hline \multicolumn{4}{|l|}{ Int.-col. } \\
\hline Pre & $53.7 \pm 32.6$ & $56.4 \pm 28.0$ & $53.0 \pm 15.5$ \\
\hline Post & $73.7 \pm 66.7$ & $47.9 \pm 34.2 *$ & $40.1 \pm 23.0$ \\
\hline \multicolumn{4}{|c|}{ Int.-word } \\
\hline Pre & $74.3 \pm 43.4$ & $78.1 \pm 35.0$ & $77.4 \pm 35.0$ \\
\hline Post & $98.4 \pm 77.7^{+}$ & $67.2 \pm 41.5^{+}$ & $61.9 \pm 20.6$ \\
\hline \multicolumn{4}{|l|}{ Errors } \\
\hline Pre & $2.5 \pm 3.3$ & $4.2 \pm 6.1$ & $4.7 \pm 7.7$ \\
\hline Post & $2.3 \pm 1.9$ & $0.4 \pm 0.8 * *$ & $0.6 \pm 0.9 *$ \\
\hline
\end{tabular}

Significant changes of the parameters over the course of the treatment and trends thereof were marked $\left({ }^{+} p<0.1, * p<0.05\right.$, *** $p<0.0$ I).

Stroop test. The ANOVA conducted for the two interference difference scores (interference time-color naming, and interference time - word reading) revealed significant interactions 'time $\times$ medication' $\left(\mathrm{F}_{2,35}=4.29\right.$ and 5.44, respectively, $p<0.05$ and 0.01 , respectively). These interactions were due to the fact that within the typically medicated group patients needed longer to overcome the cognitive interference created by this task at the follow-up as compared to the baseline testing $\left(t_{9}=1.71\right.$, NS and $t_{9}=1.81, p<0.1$, for the difference measures 'interference-color naming' and 'interference-word reading', respectively), whereas the other two groups completed the task more quickly at the 6-week-follow-up testing (atypical group: $t_{18}=1.67$, NS and $t_{18}=2.03, p<0.1$, respectively; combined group: $t_{8}=1.39 / 1.68$, NS; cf. Table 3 ).

As the errors made during the Stroop interference condition were not normally distributed, Wilcoxon's test was used to analyze changes from baseline to follow-up. In the group of patients receiving typical antipsychotic medication the error rate remained almost unchanged (cf. Table 3; $Z=-0.17, \mathrm{NS}$ ), whereas patients receiving atypical medication alone or in combination with typical antipsychotics made more errors at baseline than at follow up $(Z=-3.00, p<0.01$ and $Z=-2.56, p<0.05$, respectively).

\section{Exploratory Correlation Analyses}

Exploratory correlation analyses were performed to test whether the change of the NGA during treatment (baseline

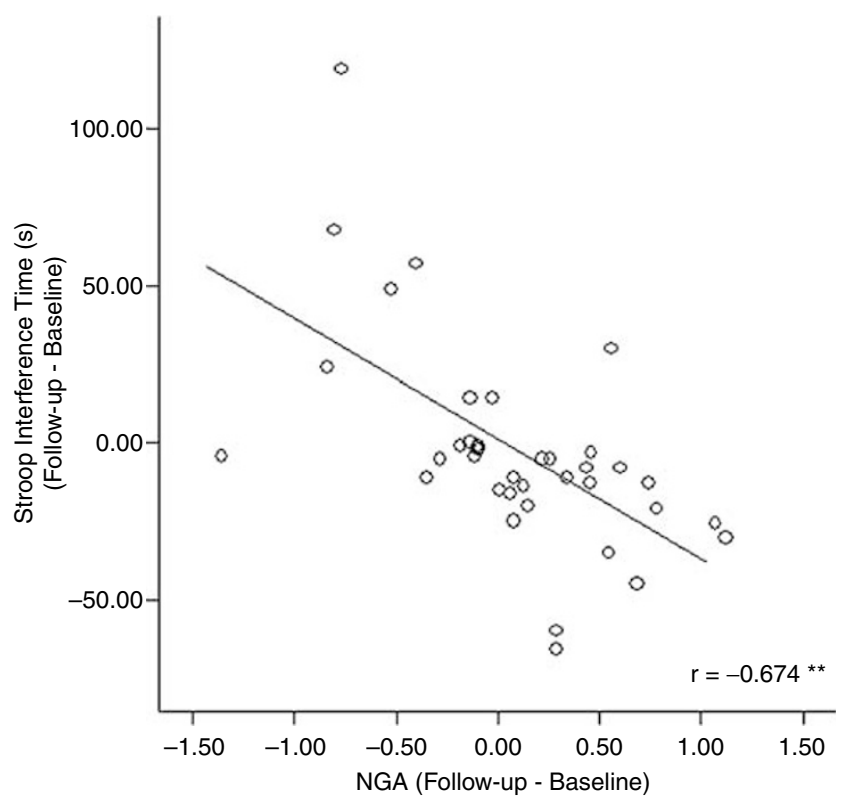

Figure 3 Correlation between changes in Stroop interference time (corrected for word reading) and changes in the NGA over the course of the treatment.

$v s$ follow-up) correlated with a respective change in the neuropsychological or psychometric variables. Only one statistically significant correlation was revealed: The change of the NGA over time $\left(\mathrm{NGA}_{\text {follow-up }}-\mathrm{NGA}_{\text {baseline }}\right)$ correlated with the change in Stroop interference time (corrected for either word reading or color naming; Interference time $_{\text {follow-up }}-$ Interference time baseline $_{\text {e }} \quad r=-0.674 /$ $r=-0.599, p<0.001)$, an improvement in the NGA being associated with a decrease in Stroop interference time (Figure 3).

\section{DISCUSSION}

The reported analyses suggest that atypical and typical antipsychotics exert a differential influence on the NGA as an electrophysiological marker of prefrontal brain function: whereas there was a trend to an increase in the NGA after 6 weeks of treatment with atypical antipsychotics and a significant increase in the combined group, patients treated with typical antipsychotics alone tended to have a decreased NGA at the follow-up testing. This resulted in a significantly diminished NGA after 6 weeks of treatment in the group of typically medicated patients as compared to the two groups treated with atypical antipsychotics, even though the NGA did not differ significantly between groups at the baseline measurement. The electrophysiological measure of the NGA has been suggested to reflect the function of a key structure within the prefrontal cortex, the ACC, during a response inhibition task. Therefore, an improvement of this index of prefrontal brain function owing to treatment with atypical antipsychotics, as well as a decrease of this parameter under typical antipsychotics, supports the study's hypothesis.

This differential effect of atypical $v s$ typical antipsychotic treatment on prefrontal brain function as indicated by the NGA is further corroborated by the neuropsychological findings: ANOVA for the behavioral measures in the VFT 
and also in the Stroop test (particularly interference time) indicated a significantly different effect between groups with a pattern of improvement in the atypical and the combined group and a deterioration in the typical group. Similarly, both groups of patients treated with atypical compounds made significantly fewer errors in the Stroop interference condition at follow-up than at baseline, whereas the error rates in the group of patients receiving typical antipsychotics remained basically unchanged.

Overall, the findings of this study are in line with the notion that atypical antipsychotics improve prefrontal brain functions (Braus et al, 2001; Ende et al, 2000; Honey et al, 1999; Ichikawa et al, 2002; Pehek and Yamamoto, 1994), whereas typical antipsychotics exert a less pronounced positive effect (Ichikawa et al, 2002; Li et al, 1998) or even interfere with prefrontal functioning (Bartlett et al, 1994; Braus et al, 2001; Madsen et al, 1998; Miller et al, 2001). Furthermore, our data are compatible with a number of previous studies indicating a superior effect of atypical antipsychotics on neurocognitive functioning in schizophrenic patients (Bilder et al, 2002; Braus et al, 2002; Cuesta et al, 2001; Gallhofer et al, 1996; Green et al, 1997; Lee et al, 1994; Purdon et al, 2001; Stip and Lussier, 1996; Velligan et al, 2002). The fact that the group of patients treated with a combination of typical and atypical antipsychotics showed results very similar to the atypically medicated group without any signs for an adverse effect of the typical compounds is not easily interpreted but seems to indicate nonlinear interactions between the two groups of neuroleptic drugs.

Moreover, the changes of the NGA over time correlated significantly with the changes in Stroop interference time (Figure 3) but not with the change in the number of words produced in the two versions of the VFT. This significant correlation is plausible as both the NGA and Stroop interference time are thought to reflect activity of the ACC. The VFT is also considered to activate prefrontal brain structures but - besides the Broca area-preferentially the DLPFC and not the ACC. In accordance with this notion, changes in Stroop interference performance significantly correlated with changes in the NGA as an index of ACC activity, whereas changes in VFT performance did not.

One weakness of this clinical study is certainly the absence of a randomization procedure for the different treatment groups. However, sound statistical analyses of patient variables (age, gender, handedness, diagnoses, number of previous hospital treatments, and duration of disease), psychometric scores (HDRS; PANSS: Positive, Negative, Global Symptomatology and total score; BPRS) and the initial NGA did not reveal any significant differences between groups at baseline. Regarding the neurocognitive measures (number of words in the letters and categories version of the VFT; Stroop word reading, color naming, and interference time; CPT performance), only the number of words in the categories version of the VFT tended to differ between the typically and the atypically medicated group of patients at baseline. None of the other neuropsychological scores revealed a significant difference between any of the groups at the initial testing $(p>0.35)$. The absence of meaningful initial differences between the three groups of patients indicates a sufficient homogeneity between groups, which allows a thorough interpretation of the results. However, as it is impossible to completely rule out the possibility that selection effects based on covariates beyond the ones discussed above were responsible for the observed group differences, future studies with randomly assigned medication groups seem inevitable. Moreover, the relatively small and unequal sample sizes and the resulting statistical findings, that do not allow a completely unequivocal interpretation of the results, put further emphasis on the necessity of replication studies with larger sample sizes in order to verify and further investigate the differential effect of typical and atypical antipsychotics (and their interaction) on prefrontal brain function. Also, when interpreting the present findings it should be kept in mind that these might not be representative for the entire population of schizophrenic patients (relatively high percentage of female patients and relatively high mean age in the present patient sample; see Method section). Finally, future investigations in the field should be designed to test the predictive value of an initially diminished NGA for the treatment response to atypical antipsychotics.

\section{ACKNOWLEDGEMENTS}

We would like to thank Inge Gröbner, Melanie Harder, and Ireen Schaffrath for their skilled technical assistance. This study was supported by the Deutsche Forschungsgemeinschaft (DFG Fa $361 / 8-1+2$ to AJF).

\section{REFERENCES}

Andreasen NC, Rezai K, Alliger R, Swayze VW, Flaum M, Kirchner $\mathrm{P}$ et al (1992). Hypofrontality in neuroleptic-naive patients with Xenon 133 single-photon emission computed tomography and the tower of London. Arch Gen Psychiatry 49: 943-958.

Barch DM, Braver TS, Akbudak E, Conturo T, Ollinger J, Snyder A (2001). Anterior cingulate cortex and response conflict: effects of response modality and processing domain. Cereb Cortex 11: 837-848.

Bartlett EJ, Brodie JD, Simkowitz P, Dewey SL, Rusinek H, Wolf AP et al (1994). Effects of haloperidol challenge on regional cerebral glucose utilization in normal human subjects. Am J Psychiatry 151: 681-686.

Bilder RM, Goldman RS, Volavka J, Czobor P, Hoptman M, Sheitman B et al (2002). Neurocognitive effects of clozapine, olanzapine, risperidone, and haloperidol in patients with chronic schizophrenia or schizoaffective disorder. Am J Psychiatry 159: 1018-1028.

Borison RL (1996). The role of cognition in the risk-benefit and safety analysis of antipsychotic medication. Acta Psychiatr Scand Suppl 389: 5-11.

Braus DF, Ende G, Weber-Fahr W, Demirakca T, Henn FA (2001). Favorable effect on neuronal viability in the anterior cingulate gyrus due to long-term treatment with atypical antipsychotics: an MRSI study. Pharmacopsychiatry 34: 251-253.

Braus DF, Ende G, Weber-Fahr W, Demirakca T, Tost H, Henn FA (2002). Functioning and neuronal viability of the anterior cingulate neurons following antipsychotic treatment: MRspectroscopic imaging in chronic schizophrenia. Eur Neuropsychopharmacol 12: 145-152.

Carter CS, MacDonald AW, Ross LL, Stenger VA (2001). Anterior cingulate cortex activity and impaired self-monitoring of 
performance in patients with schizophrenia: an event-related fMRI study. Am J Psychiatry 158: 1423-1428.

Carter CS, Mintun M, Nichols T, Cohen JD (1997). Anterior cingulate gyrus dysfunction and selective attention deficits in

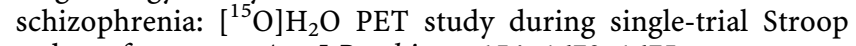
task performance. Am J Psychiatry 154: 1670-1675.

Carter CS, Perlstein W, Ganguli R, Brar J, Mintun M, Cohen JD (1998). Functional hypofrontality and working memory dysfunction in schizophrenia. Am J Psychiatry 155: 1285-1287.

Cuenod CA, Bookheimer SY, Hertz-Pannier L, Zeffiro TA, Theodore WH, Le Bihan D (1995). Functional MRI during word generation, using conventional equipment: a potential tool for language localization in the clinical environment. Neurology 45: 1821-1827.

Cuesta MJ, Peralta V, Zarzuela A (2001). Effects of olanzapine and other antipsychotics on cognitive function in chronic schizophrenia: a longitudinal study. Schizophr Res 48: 17-28.

de Zubicaray GI, Zelaya FO, Andrew C, Williams SC, Bullmore ET (2000). Cerebral regions associated with verbal response initiation, suppression and strategy use. Neuropsychologia 38: 1292-1304.

Díaz-Mataix L, Scorza MC, Bortolozzi A, Toth M, Celada P, Artigas $\mathrm{F}$ (2005). Involvement of 5- $\mathrm{HT}_{1 \mathrm{~A}}$ receptors in prefrontal cortex in the modulation of dopaminergic activity: role in atypical antipsychotic action. J Neurosci 25: 10831-10843.

Dickins DW, Singh KD, Roberts N, Burns P, Downes JJ, Jimmieson $\mathrm{P}$ et al (2001). An fMRI study of stimulus equivalence. Neuroreport 12: 405-411.

Dolan R, Frith CD, Friston KJ, Frackowiak RSJ, Grasby PM (1995). Dopaminergic modulation of impared cognitive activation in the ACG in schizophrenia. Nature 378: 180-183.

Ende G, Braus DF, Walter S, Weber-Fahr W, Soher B, Maudsley AA et al (2000). Effects of age, medication, and illness duration on the $\mathrm{N}$-acetyl-aspartate signal of the anterior cingulate region in schizophrenia. Schizophr Res 41: 389-395.

Fallgatter AJ, Aranda DR, Bartsch AJ, Herrmann MJ (2002a). Longterm reliability of electrophysiologic response control parameters. J Clin Neurophysiol 19: 61-66.

Fallgatter AJ, Bartsch AJ, Eisenack S, Neuhauser B, Aranda D, Herrmann MJ (2001). Reliability of electrophysiological parameters assessing human motor control. Clin Neurophysiol 112: 198-204.

Fallgatter AJ, Bartsch AJ, Herrmann MJ (2002b). Electrophysiological measurements of anterior cingulate function. J Neural Transm 109: 977-988.

Fallgatter AJ, Bartsch AJ, Zielasek J, Herrmann MJ (2003). Brainelectrical dysfunction of the anterior cingulate in schizophrenic patients. Psychiatry Res 124: 37-48.

Fallgatter AJ, Brandeis D, Strik WK (1997). A robust assessment of the NoGo-anteriorisation of P300 microstates in a cued continuous performance test. Brain Topogr 9: 295-302.

Fallgatter AJ, Eisenack SS, Neuhauser B, Aranda D, Scheuerpflug P, Herrmann MJ (2000). Stability of late event-related potentials: topographical descriptors of motor control compared with the P300 amplitude. Brain Topogr 12: 255-261.

Fallgatter AJ, Mueller TJ (2001). Electrophysiological signs of reduced prefrontal response control in schizophrenic patients. Psychiatry Res 107: 19-28.

Fallgatter AJ, Müller TJ, Strik WK (1999). Age-related changes in brain electrical correlates of response control. Clin Neurophysiol 110: $833-838$.

Fallgatter AJ, Strik WK (1999). The NoGo-anteriorisation as a neurophysiological standard-index for cognitive response control. Int J Psychophysiol 32: 115-120.

Ford JM, Gray M, Whitfield SL, Turken AU, Glover G, Faustman WO et al (2004). Acquiring and inhibiting prepotent responses in schizophrenia: event-related brain potentials and functional magnetic resonance imaging. Arch Gen Psychiatry 61: 119-129.
Gaillard WD, Hertz-Pannier L, Mott SH, Barnett AS, LeBihan D, Theodore WH (2000). Functional anatomy of cognitive development: fMRI of verbal fluency in children and adults. Neurology 54: 180-185.

Gallhofer B, Bauer U, Lis S, Krieger S, Gruppe H (1996). Cognitive dysfunction in schizophrenia: comparison of treatment with atypical antipsychotic agents and conventional neuroleptic drugs. Eur Neuropsychopharmacol 6(Suppl 2): 13-20.

Glahn DC, Ragland JD, Abramoff A, Barrett J, Laird AR, Bearden CE et al (2005). Beyond hypofrontality: a quantitative metaanalysis of functional neuroimaging studies of working memory in schizophrenia. Hum Brain Mapp 25: 60-69.

Goldberg TE, Hyde TM, Kleinman JE, Weinberger DR (1993). Course of schizophrenia: neuropsychological evidence for a static encephalopathy. Schizophr Bull 19: 797-804.

Gratton G, Coles MGH (1989). Generalization and evaluation of eye-movement correction procedures. J Psychophysiol 3: 1-50.

Green MF, Marshall Jr BD, Wirshing WC, Ames D, Marder SR, McGurk S et al (1997). Does risperidone improve verbal working memory in treatment-resistant schizophrenia? Am J Psychiatry 154: 799-804.

Gur RE, Kohler C, Ragland JD, Siegel SJ, Bilker WB, Loughead J et al (2003). Neurocognitive performance and clinical changes in olanzapine-treated patients with schizophrenia. Neuropsychopharmacology 28: 2029-2036.

Hamilton M (1960). A rating scale for depression. J Neurol Neurosurg Psychiatry 23: 56-62.

Haznedar MM, Buchsbaum MS, Luu C, Hazlett EA, Siegel Jr BV, Lohr J et al (1997). Decreased anterior cingulate gyrus metabolic rate in schizophrenia. Am J Psychiatry 154: 682-684.

Honey GD, Bullmore ET, Soni W, Varatheesan M, Williams SC, Sharma T (1999). Differences in frontal cortical activation by a working memory task after substitution of risperidone for typical antipsychotic drugs in patients with schizophrenia. Proc Natl Acad Sci USA 96: 13432-13437.

Horacek J, Bubenikova-Valesova V, Kopecek M, Palenicek T, Dockery C, Mohr P et al (2006). Mechanism of action of atypical antipsychotic drugs and the neurobiology of schizophrenia. CNS-drugs 20: 389-409.

Ichikawa J, Dai J, O'Laughlin IA, Fowler WL, Meltzer HY (2002). Atypical, but not typical, antipsychotic drugs increase cortical acetylcholine release without an effect in the nucleus accumbens or striatum. Neuropsychopharmacology 26: 325-339.

Ichikawa J, Meltzer HY (1999). Relationship between dopaminergic and serotonergic neuronal activity in the frontal cortex and the action of typical and atypical antipsychotic drugs. Eur Arch Psychiatry Clin Neurosci 249(Suppl 4): 90-98.

Ingvar DH, Franzen G (1974). Abnormalities of cerebral blood flow distribution in patients with chronic schizophrenia. Acta Psychiatr Scand 50: 425-462.

Kay SR, Fiszbein A, Opler LA (1987). The Positive and Negative Syndrome Scale (PANSS) for schizophrenia. Schizophr Bull 13: 261-277.

Laurens KR, Ngan ET, Bates AT, Kiehl KA, Liddle PF (2003). Rostral anterior cingulate cortex dysfunction during error processing in schizophrenia. Brain 126: 610-622.

Laux G, Dietmaier O, Koenig W (2000). Pharmakopsychiatrie, 3rd edn. Urban \& Fischer, Muenchen. p 237.

Lee MA, Thompson PA, Meltzer HY (1994). Effects of clozapine on cognitive function in schizophrenia. J Clin Psychiatry 55(Suppl B): 82-87.

Lehmann D (1987). Principles of spatial analysis. In: Gevins A, Remond A (eds). Handbook of Electroencephalography and Clinical Neurophysiology, Vol. 1: Methods of Analysis of Brain Electrical and Magnetic Signals. Elsevier: Amsterdam. pp 309-354.

Lewander T (1994). Neuroleptics and the neuroleptic-induced deficit syndrome. Acta Psychiatr Scand Suppl 380: 8-13. 
Li XM, Perry KW, Wong DT, Bymaster FP (1998). Olanzapine increases in vivo dopamine and norepinephrine release in reat prefrontal cortex, nucleus accumbens and striatum. Psychopharmacol 136: 153-161.

MacDonald III AW, Carter CS (2003). Event-related FMRI study of context processing in dorsolateral prefrontal cortex of patients with schizophrenia. J Abnorm Psychol 112: 689-697.

Madsen AL, Keiding N, Karle A, Esbjerg S, Hemmingsen R (1998). Neuroleptics in progressive structural brain abnormalities in psychiatric illness. Lancet 352: 784-785.

Matthews SC, Paulus MP, Simmons AN, Nelesen RA, Dimsdale JE (2004). Functional subdivisions within anterior cingulate cortex and their relationship to autonomic nervous system function. NeuroImage 22: 1151-1156.

Miller DD, Andreasen NC, O'Leary DS, Watkins GL, Boles Ponto LL, Hichwa RD (2001). Comparison of the effects of risperidone and haloperidol on regional cerebral blood flow in schizophrenia. Biol Psychiatry 49: 704-715.

Overall JE, Gorham DR (1962). The brief psychiatric rating scale. Psychol Rev 10: 799-812.

Pascual-Marqui RD, Michel CM, Lehmann D (1994). Low resolution electromagnetic tomography, a new method for localizing electrical activity in the brain. Int J Psychophysiol 18: 49-65.

Pehek EA, Yamamoto BK (1994). Differential effects of locally administered clozapine and haloperidol on dopamine efflux in the rat prefrontal cortex and caudate-putamen. J Neurochem 63: 2118-2124.

Purdon SE, Jones BDW, Stip E, Labelle A, Addington D, David SR et al (2000). Neuropsychological change in early pahse schizophrenia during 12 months of treatment with olanzapine, risperidone, or haloperidol. Arch Gen Psychiatry 57: 249-258.

Purdon SE, Malla A, Labelle A, Lit W (2001). Neuropsychological change in patients with schizophrenia after treatment with quetiapine or haloperidol. J Psychiatry Neurosci 26: 137-149.

Riley EM, McGovern D, Mockler D, Doku VC, O'Ceallaigh S, Fannon DG et al (2000). Neuropsychological functioning in firstepisode psychosis - evidence of specific deficits. Schizophr Res 43: $47-55$.

Rodriguez-Sanchez JM, Crespo-Facorro B, Iglesias RP, Bosch CG, Alvarez M, Llorca J et al (2005). Prefrontal cognitive functions in stabilized first-episode patients with schizophrenia spectrum disorders: a dissociation between dorsolateral and orbitofrontal functioning. Schizophr Res 77: 279-288.

Rosvold HE, Mirsky A, Sarason I, Bransome Jr ED, Beck LH (1956). A continuous performance test of brain damage. J Consult Psychol 20: 343-350.
Rubia K, Russell T, Bullmore ET, Soni W, Brammer MJ, Simmons A et al (2001). An fMRI study of reduced left prefrontal activation in schizophrenia during normal inhibitory function. Schizophr Res 52: 47-55.

Ruff CC, Woodward TS, Laurens KR, Liddle PF (2001). The role of the anterior cingulate cortex in conflict processing: evidence from reverse stroop interference. NeuroImage 14: 1150-1158.

Siegel Jr BV, Buchsbaum MS, Bunney Jr WE, Gottschalk LA, Haier RJ, Lohr JB et al (1993). Cortical-striatal-thalamic circuits and brain glucose metabolic activity in 70 unmedicated male schizophrenic patients. Am J Psychiatry 150: 1325-1336.

Stip E, Lussier I (1996). Effect of risperidone on cognition in patients with schizophrenia. Can J Psychiatry 41(Suppl 8): $35-40$.

Strik WK, Fallgatter AJ, Brandeis D, Pascual-Marqui R (1998). Three dimensional tomography of event-related potentials during response inhibition: evidence for phasic frontal lobe activation. Electroencephalogr Clin Neurophysiol 108: $406-413$.

Stroop JR (1935). Studies of interference in serial verbal reactions. I Exp Psychol 18: 643-662.

Swick D, Jovanovic J (2002). Anterior cingulate cortex and the Stroop task: neuropsychological evidence for topographic specificity. Neuropsychologia 40: 1240-1253.

Tamminga CA, Thaker GK, Buchanan R, Kirkpatrick B, Alphs LD, Chase TN et al (1992). Limbic system abnormalities identified in schizophrenia with fluorodeoxyglucose and neocortical alterations with the deficit syndrome. Arch Gen Psychiatry 49: 522-530.

Velligan DI, Newcomer J, Pultz J, Csernansky J, Hoff AL, Mahurin $\mathrm{R}$ et al (2002). Does cognitive function improve with quetiapine in comparison to haloperidol? Schizophr Res 53: 239-248.

Volz H, Gaser C, Hager F, Rzanny R, Ponisch J, Mentzel H et al (1999). Decreased frontal activation in schizophrenics during stimulation with the continuous performance test - a functional magnetic resonance imaging study. Eur Psychiatry 14: 17-24.

Wittchen HU, Zaudig M, Fydrich T (1997). Strukturiertes Klinisches Interview für DSM-IV (SKID I und II). Deutsche Bearbeitung. Hogrefe: Göttingen.

Woods SW (2003). Chlorpromazine equivalent doses for the newer atypical antipsychotics. J Clin Psychiatry 64: 663-667.

Woodward ND, Purdon SE, Meltzer HY, Zald DH (2005). A metaanalysis of neuropsychological change to clozapine, olanzapine, quetiapine, and risperidone in schizophrenia. Int J Neuropsychopharmacol 8: 457-472. 